\section{Missing link at Sellafield}

SIR-In 1927, when Hermann Muller showed that X-rays induce mutations in the common fruitfly Drosophila melanogaster, he did so by irradiating male fruitflies and looking for lethal mutations in their offspring. Within a year, most of the mutations were shown to be associated with deletions, inversions and translocations in the chromosomes. We now know that cells can repair such breaks. But in cells that divide repeatedly (such as the stem cells in the blood and skin and spermatogonia), the broken pieces sometimes rearrange themselves during mitotic division. Once chromosomes have been rearranged, the cell has no repair mechanism: if the rearrangement is passed down through the germ cells, it is in the genome for ever.

That mutations can be caused by breaks in chromosomes was shown by a combination of cytology and genetics in 1928; it was confirmed in the 1930 s when the banding pattern of giant salivary chromosomes gave Drosophila cytologists increased resolution; it is the basis of much of the present-day search by molecular biologists for genes involved in human cancer. The breakpoints in chromosomal rearrangements associated with particular somatic (and hereditary) cancers are being used to find and characterize the genes they have disrupted.

Your leading article is correct in stating that statistics cannot prove causality

\section{Italian knowhow}

SIR-Although the issue of cuts in money given to universities by governments has been bothering scientists - and others in many countries, and your journal has provided accurate and often critical coverage, little attention has been paid to the Italian way of problem-solving in this field, which may prove the ultimate superiority of Mediterranean pragmatism.

Government funds for research are on the one hand managed locally by the universities, and on the other given directly by the ministry to research groups - or, better, to consortia of research teams. The latter amount to 40 per cent of the total of funds given each year (and are commonly referred to as " 40 per cent funds").

The amount of these funds has dropped in recent years in real terms, but this is not the real trick. Our government has chosen a more subtle and more enterprising way, by stretching the duration of the financial year. Funds for the year 1985 were actually available to the research groups in May 1985; 1986 funds in October 1986; 1987 funds in January 1988. Things went better the following year, as 1988 funds arrived in January 1989; as for the 1990 money, no one knows, at the moment,
(Nature 344, 90; 1989). But basic science can. It is time for the scientific community to stand up and say so, with all the authority it can and should command. A spokeswoman for British Nuclear Fuels Limited is quoted as saying that the Gardner report into cases of leukaemia among children of workers at Sellafield "indicates a link but does not show a causal relationship" (Brit. med. J., 300, 627; 1990). Indeed. But molecular genetics can do better than that.

Muller also showed that it is the cumulative dose of radiation that is important for heritable effects, not the dose received on a single occasion.

If I were a parent at Sellafield, I would not be too worried about face-to-face interviews. I would be asking for chromosome spreads and the very best that molecular genetics can offer. We should make sure that those families get help without a struggle. Childhood leukaemias will not be the only dominant mutations. And there are all the recessives.

GUIL WINCHESTER

\section{Sutherland Avenue,}

London W13 8LE, UK

\section{Japanese invention}

SIR-A recent book review (Nature $\mathbf{3 4 3}$, 225-226; 1990), which discusses originality in Japanese research, will be welcomed by many Japanese scientists. However,

when it will reach our thirsty laboratories, but, since it usually takes some time from the formal announcement to the actual availability of the grants, they are not likely to be at the disposal of local groups for two or three months at best. The dates reported are for groups at Turin University, but they are more or less the same for the whole country. So, in five years, only four annual grants have been made, with a net saving of more than 20 per cent for the state budget. Additional handicaps are provided by constantly changing paperwork and application rules. No one seems to have protested against this rather bold way of managing public funds, and everyone is happy when the beloved money arrives.

The approach has survived several changes of ministers and even a change of ministry (last year, universities were separated from the Ministry of Education and a new Ministry for University and Scientific Research was created). It is so smooth and effective that other governments might consider following the Italian road.

\section{Laboratory of General Physiology,}

DAVID LOVISOLO

University of Torino,

I-10125 Torino, Italy for this very reason, it is incorrect to cite the quick introduction of television broadcasts and the large share of Japanesemade television sets in the US market as a case of efficient imitation of Western science.

In fact, the TV monitor was invented and built by a Japanese scientist, Kenjiro Takayanagi, in 1926. Many prototype TVs had been built before his invention; however they were of a mechanical type, having no similarity with current TV monitors, which are based on the 'allelectronic' TV made by Takayanagi. $\mathrm{He}$ also invented the mechanisms of a TV camera in 1930 independently of Dr V. Zworykin of RCA in the United States, even though he could not build it due to the weak technological background in Japan at that time. Thus Takayanagi should be credited as the inventor of TV monitor, and perhaps as the last and the only living inventor in the tradition of Thomas Edison.

The reason for the 14-year delay (described in the review) in TV broadcasting in Japan was the intervention of the Second World War. The first test broadcast in Japan occurred in 1939, as in the United States. But in Japan, all TV research and broadcast attempts were suspended by the Japanese government in 1941-42, and were subsequently restricted by the United States until 1950 .

The imbalance between the advancement of technology and inferiority in basic research in Japan seems to be mostly due to the uneven allocation of brilliant people in Japanese job markets. Most excellent students in Japan get a job in a private company as soon as they have obtained their bachelor's degree. However, masters' and $\mathrm{PhD}$ graduates are routinely rejected, or at most treated equivalently with bachelor's degree by many companies. Even though some changes have been made, openings are mostly restricted to applied areas such as engineering. Thus the imbalance in technology and science is strongly backed up by the human factor as a cultural consequence of Japanese society.

Japanese TV technology should be cited as an excellent example of the originality of Japanese invention, not as a case of imitation. The Japanese should not be viewed as excellent imitators lacking originality. It is Japanese culture that suppresses the development of originality in basic research. The apparent lack of originality in Japan's basic science, together with an excellence in imitation, is mainly due to the different 'allocation of originality' in Japan, as in the case of TV invention, which is in an applied field.

JIM YOSHIMURA

Department of Mathematics, University of British Columbia, 121-1984 Mathematics Road, Vancouver, BC V6T 1Y4, Canada 